\title{
Paradaemonia thelia (Jordan) e seus estágios imaturos (Lepidoptera, Saturniidae, Arsenurinae)
}

\author{
Eurides Furtado ${ }^{1} \&$ Fernando Corrêa Campos-Neto ${ }^{2}$ \\ ${ }^{1}$ Caixa Postal 97, 78400-000 Diamantino, Mato Grosso, Brasil. E-mail: efurtado@uaivip.com.br \\ ${ }^{2}$ Rua Corcovado 1030, Bairro Monte Castelo, 32285-000 Contagem, Minas Gerais, Brasil. \\ E-mail: fernandoccn@petrobras.com.br
}

\begin{abstract}
Paradaemonia thelia (Jordan) and its immature stages (Lepidoptera, Saturniidae, Arsenurinae). Data on immature stages, the behavior and the range of Paradaemonia thelia (Jordan, 1922) are presented. The solitary larva feed on Chrysophyllum marginatum (Hook. \& Arn.) Radlk. (Sapotaceae), its natural hostplant. Isolated ovae are deposited on dorsal surface of mature leaves. Larval development required 18 days; the pupal stage lasted 32-37 days. Adults, ovae, larvae and pupa are illustrated in color.
\end{abstract}

KEY WORDS. Biology, hostplant, Sapotaceae, spatial distribution.

RESUMO. Dados sobre os estágios imaturos, o comportamento e a distribuição de Paradaemonia thelia (Jordan) são apresentados. A larva solitária alimenta-se de Chrysophyllum marginatum (Hook. \& Arn.) Radlk. (Sapotaceae), sua planta hospedeira natural. Os ovos são postos isolados na face dorsal de folhas maduras. O desenvolvimento larval leva 18 dias e o estágio pupal 32-37 dias. Adultos, ovos, larvas e pupa são ilustrados a cores.

PALAVRAS CHAVE. Biologia, distribuição espacial, planta hospedeira, Sapotaceae.

O gênero Paradaemonia Bouvier, 1925 agrega 14 espécies de Arsenurinae neotropicais distribuídas do México ao norte da Argentina. Paradaemonia thelia (Jordan, 1922) (Figs 1-2) foi descrita de um macho procedente do Paraguai, mas sua distribuição espacial se estende ao alto Paraná na Argentina, e Brasil nos estados do Rio Grande do Sul, Santa Catarina, Paraná, São Paulo, Mato Grosso do Sul, Goiás e Distrito Federal (Lemaire 1980). Ocorre também no alto Rio Arinos, Diamantino, Mato Grosso, em Belo Horizonte e arredores e em Oliveira (20 $42^{\prime}$ 259"S, 44 50'083"W), 969 m, Minas Gerais, procedência do material estudado.

\section{MATERIAL E MÉTODOS}

Ovos e larvas jovens foram encontrados pelo segundo autor sobre Chrysophyllum marginatum (Hook. \& Arn.) Radlk. (Sapotaceae), numa área de cerrado baixo e com vegetação secundária. As larvas foram criadas em gaiolas plásticas com renovação diária da planta alimento. A identificação da planta hospedeira seguiu LoREnZI (1998).

\section{Ovo (Fig. 3)}

\section{RESULTADOS E DISCUSSÃO}

Elipsóide com os pólos achatados, esbranquiçados e com pontos e marmorizações marrom-claros; face menor anelada com marrom-claro, área central esbranquiçada; micrópila mar- rom-escura, no eixo menor. Comprimento 2,3 mm; largura 2,0 $\mathrm{mm}$; altura 1,3 mm. Período embrionário ca. 9 dias.

\section{Larva}

Primeiro ínstar (Fig. 4). Cabeça arredondada com a fronte deprimida; castanho-avermelhada, brilhante, mandíbulas marrom-escuras. Corpo com séries de escolos típicos para a maioria das espécies da tribo; os protorácicos vermelho-escuros, haste curta, grossa e com os espinhos pretos; os metatorácicos longos, bífidos, haste da coloração geral do tegumento e com anelação mediana amarela, prolongamentos da bifurcação pretos. Escolos abdominais pretos, haste eriçada com pequenos espinhos, os subespiraculares menores que os subdorsais e os dorsais; em A8 semelhante aos torácicos, porém mais curtos e como eles levemente inclinados para a frente. Pernas torácicas, abdominais e anais da coloração geral do tegumento, as abdominais com os escudos laterais escuros. Tegumento vermelho com manchas amarelas laterodorsais na área central de A1-7 onde a base dos escolos é bordada com mancha negra. Comprimento da larva ao eclodir 5,5 mm; no final do ínstar 10,0 mm. Duração três dias.

Segundo ínstar (Fig. 5). Cabeça arredondada, área frontal achatada, região ventral deprimida, vértice ligeiramente côncavo; oliváceo-brilhante, área lateral avermelhada, assim como as suturas da fronte; clípeo verde-claro; mandíbulas e estemas marrom-escuros. Pronoto com um par de escolos in- 

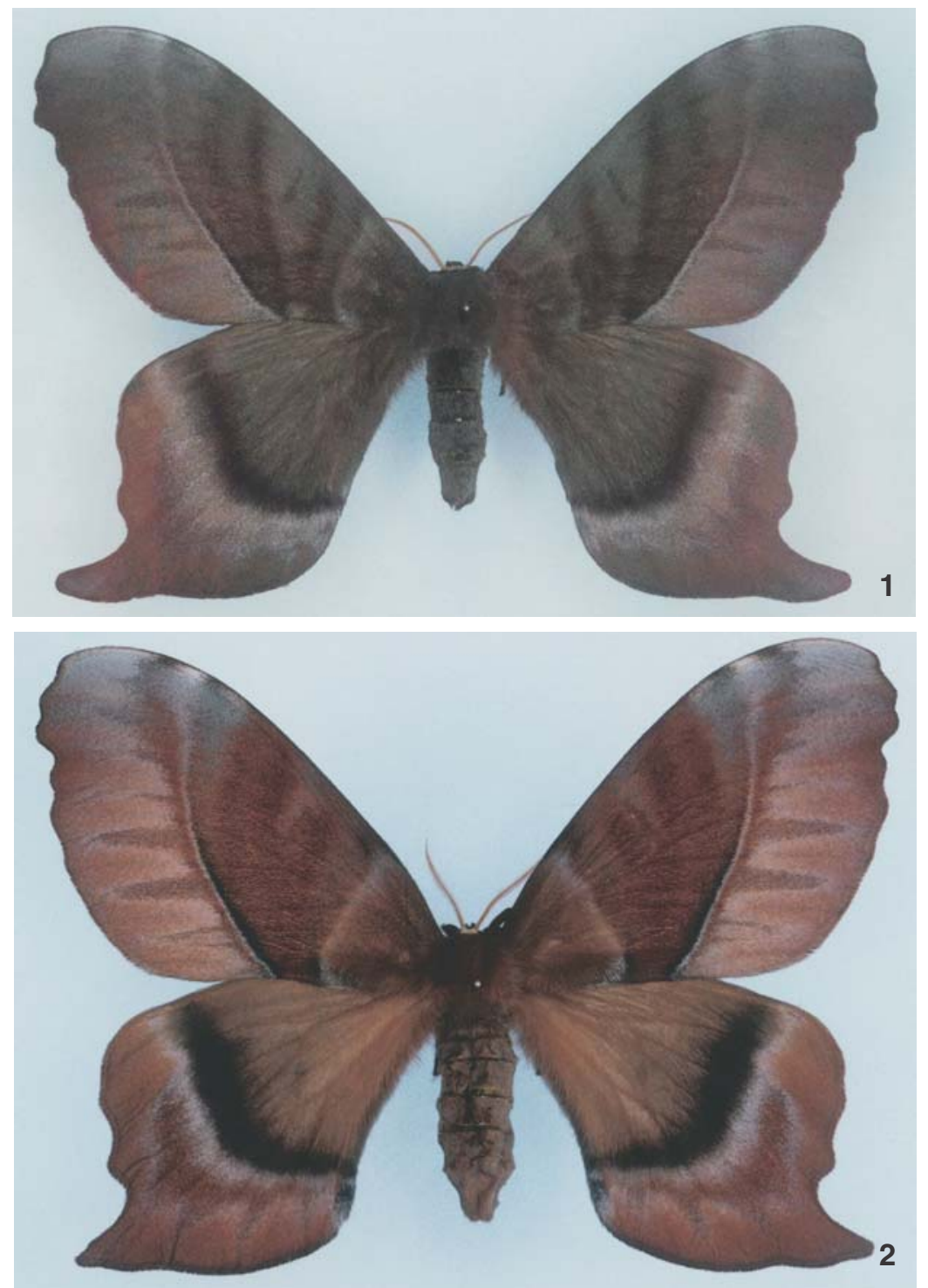

Figuras 1-2. Paradaemonia thelia, adultos, vista dorsal: (1) macho, extensão alar 91 mm; (2) fêmea, extensão alar 96 mm.

clinados lateralmente, o dorsal aproximadamente o triplo do comprimento e volume do subdorsal, ambos avermelhados com haste eriçada com pequenos espinhos mais escuros. Metanoto látero- e dorsalmente corcovado, plano e com longo escolo articulado, claviforme bisegmentado, inclinado lateralmente e para a frente, marrom-avermelhado, com haste repleta de pequenos espinhos marrom-escuros. Escolo A8 claviforme, articulado, longo aproximadamente $1 / 5$ do corpo, haste avermelhada, com espinhos negros. Pernas torácicas avermelhadas, as abdominais e as anais verde-amareladas com os escudos vermelhos. Placa suranal trapezoidal, formada com calosidade avermelhada e mesclas esbranquiçadas. Faixa espiracular ama- relo-clara encimada por estreita faixa vermelha que atinge a base dos espiráculos A2-8. Tegumento verde com pontículos esbranquiçados; linha dorsal vermelha de A2 à placa suranal; estreita e fraca faixa oblíqua amarelada em A2-8, da faixa espiracular à linha dorsal do segmento seguinte. Comprimento $13,5 \mathrm{~mm}$. Duração três dias.

Terceiro ínstar (Fig. 6). Difere do ínstar anterior pela coloração mais fraca dos escolos; na maior nitidez da faixa vermelha subespiracular em A2-8; na nitidez quase vestigial, das faixas oblíquas nestes segmentos; na faixa dorsal, agora com a área central vermelha mais clara de bordos mais intenso. Comprimento 20,0 mm. Duração dois dias. 

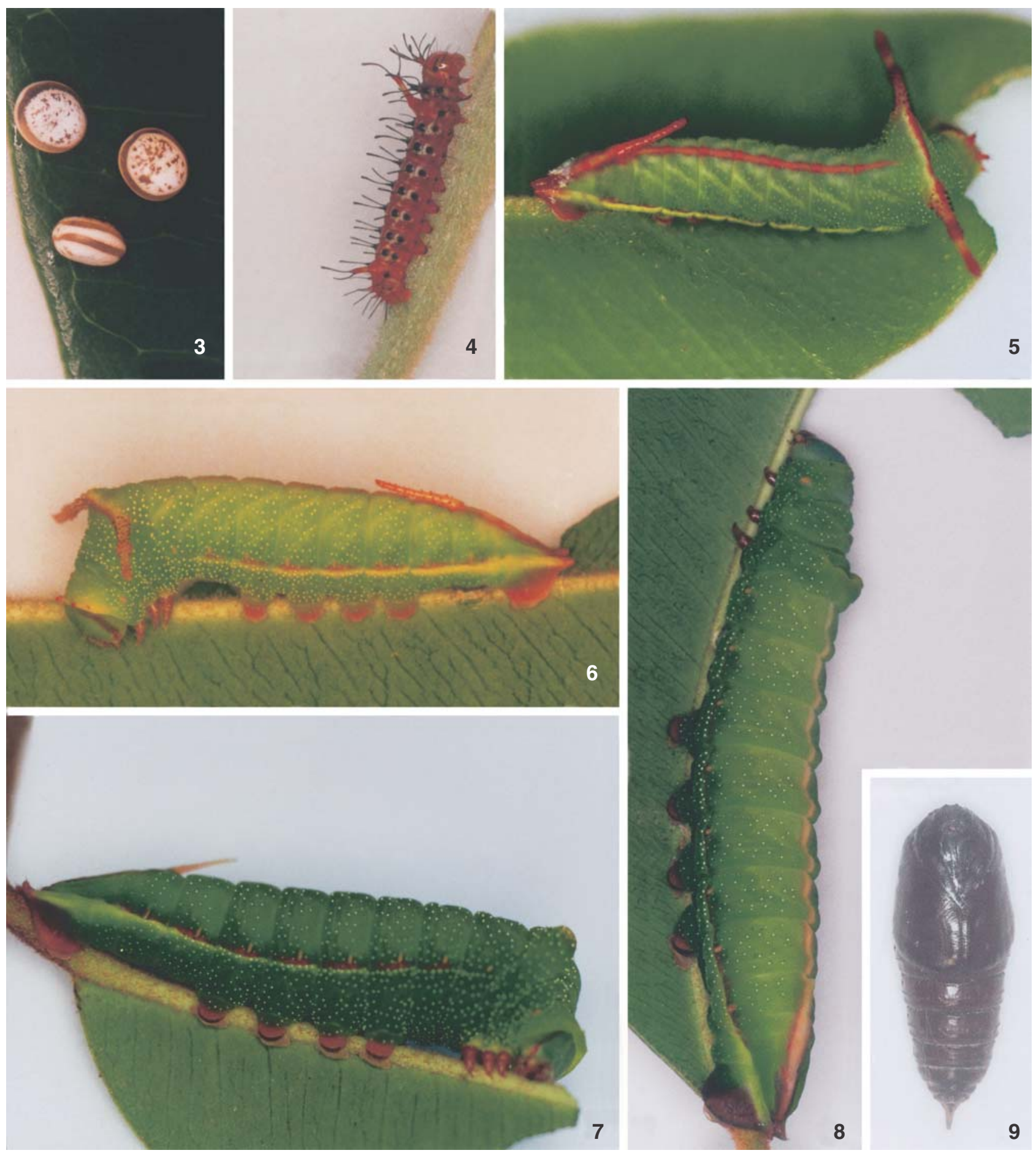

Figuras 3-9. Paradaemonia thelia: (3) ovos; (4) larva de $1^{\circ}$ ínstar, vista lateral; (5) larva de $2^{\circ}$ ínstar, vista dorsal; (6) larva de $3^{\circ}$ ínstar, vista laterodorsal; (7) larva de $4^{\circ}$ ínstar, vista lateral; (8) larva de $5^{\circ}$ ínstar, vista laterodorsal; (9) pupa, vista ventral. 
Quarto ínstar (Fig. 7). Cabeça com o mesmo formato anterior, área frontal rugosa, verde-olivácea; fronte com as suturas sulcadas; áreas estematal e labral avermelhadas, com estemas e as mandíbulas negras. Desaparecem os escolos proto- e metatorácicos e o de A8 é menor que no ínstar anterior, deitado sobre a linha dorsal, confundindo-se com esta. Pronoto com a borda anterior amarelada; metanoto lateralmente coniforme, com o ápice ligado numa faixa amarela com a borda anterior vermelha, perpendicular à linha dorsal. Tegumento verde, com pontículos brancos até a área subdorsal. Faixa espiracular da cor do tegumento, com os pontículos brancos mais adensados, sobretudo em A2-7; área espiracular vermelha em A2-8. Espiráculos elipsoidais, avermelhados, com o peritrema mais escuro. Pernas torácicas avermelhadas com esparsas cerdas mais claras; as abdominais da cor do tegumento, com os escudos avermelhados com a área mediana bordada com uma faixa horizontal preta, a porção ventral com a coloração mais clara e com esparsas cerdas ainda mais claras; as anais em sua maior parte avermelhadas. Comprimento 30,0 mm. Duração três dias.

Quinto ínstar (Fig. 8). Pouco difere do ínstar anterior. Desaparecem a borda amarela do protórax e o escolo A8, este agora como pequena verruga coniforme. Em alguns indivíduos a área espiracular apresenta a coloração vermelha; faixa transversal no metatórax mais fraca e com a borda vermelha pouco visível. Comprimento 52,0 mm. Duração sete dias.

\section{Pupa (Fig. 9)}

Região da cabeça e área periférica com rugosidade média; vértice com duas calosidades aculeoladas; antenas e pernas com estrias transversais, estas sulcadas; tórax com rugosidade fina, linha dorsal marcada como fina linha protuberante, espiráculo fortemente sulcado no limite lateral entre os dois primeiros seg- mentos; espiráculo metatorácico arredondado, fortemente côncavo. Estojo das asas repleto de estrias, mais adensadas na área axilar. Segmentos abdominais parcialmente lisos, com calosidade lateral em A1-3 e ventral em A5-7; A10 sulcado e rugoso ventralmente; cremaster sagital com o ápice agudo; espiráculos elipsoidais, peritrema preto. Tegumento marrom-escuro, quase preto, com nuanças avermelhadas no estojo das asas e nos segmentos abdominais. Comprimento 35,0 mm; largura lateral 13,5 $\mathrm{mm}$ e ventral 13,0 mm. Período pupal 32-37 dias.

\section{Dados bionômicos}

O ovo é posto isoladamente e na maioria das vezes na face superior de folhas maduras, geralmente em brotações próximas ao solo.

A partir do segundo ínstar, quando em repouso a larva se mantém fixa pelas pernas abdominais, retrai o tórax e respectivas pernas e eleva-se obliquamente do substrato, inclina o escolo A8 para a frente junto à linha dorsal, confundindo-o com esta pela coloração similar. Do quarto ínstar em diante, ao ser tocada, retrai o tórax e emite uma estridulência semelhante a um chiado.

O ciclo evolutivo foi de 59-64 dias: 27 dias da postura à pré-pupa e 32-37 dias à eclosão do imago.

\section{REFERÊNCIAS BIBLIOGRÁFICAS}

Lemaire, C. 1980. Les Attacidae Americains. The Attacidae of America (= Saturniidae), Arsenurinae. Neuvilly-sur-Seine, Ed. C. Lemaire, 199p.

LorenzI, H. 1998. Árvores Brasileiras. Manual de Identificação e Cultivo de Plantas Arbóreas Nativas do Brasil. Nova Odessa, Instituto Plantarum, vol. 2, 352p.

Recebido em 04.V.2004; aceito em 24.XI.2004. 